\title{
Malignant Trophoblastic Teratoma
}

National Cancer Institute

\section{Source}

National Cancer Institute. Malignant Trophoblastic Teratoma. NCI Thesaurus. Code C66778.

A malignant germ cell tumor which metastasizes widely and produces high levels of human chorionic gonadotropin. 